\title{
Cytotoxic, apoptotic, and genetic evaluations of Nigella sativa essential oil nanoemulsion against human hepatocellular carcinoma cell lines
}

\author{
Ahmed A. Abd-Rabou ${ }^{1 *}$ and Amr E. Edris ${ }^{2^{*}}$
}

\author{
*Correspondence: \\ ahmedchemia87@yahoo.com; \\ amr_edris@hotmail.com \\ ${ }^{1}$ Hormones Department, \\ Medical Research and Clinical \\ Studies Institute, National \\ Research Center, Dokki, B.O. \\ Box 12622, Cairo, Egypt \\ ${ }^{2}$ Aroma \& Flavor Chemistry \\ Department, Food Industries \\ \& Nutrition Institute, National \\ Research Center, Dokki, B.O. \\ Box 12622, Cairo, Egypt
}

\begin{abstract}
Background: Phytochemicals and plant extracts are showing promising anticancer potentials. In the current study, the volatile faction (essential oil) of Nigella sativa seeds was evaluated against some hepatocellular carcinoma (HCC). The essential oil was extracted and characterized by chromatographic techniques to reveal its chemical composition, especially thymoquinone. Then, the oil was fabricated in two nanoemulsion formulations (F1 and F2), which differ in their composition of surfactants. The cytotoxicity and apoptotic activities of the essential oil and its nanoemulsions were evaluated in vitro against HepG2 and Huh-7 cell lines. Normal WI-38 cell line was also included in that evaluation to study the selectivity and safety of the different formulations on normal cells.

Results: Gas chromatographic analysis indicated that the essential oil is composed mainly of p-cymene (40.0\%), thymoquinone (31.2\%) and trans-a-thujene (12.8\%). Particle size of the nanoemulsions ranged between 9.4 and $119.7 \mathrm{~nm}$ depending on the type of surfactant used in the formulation process. The pure essential oil and its two nanoemulsions (F1 and F2) showed dose-dependent antiproliferative activity against both HCC cells. This activity reached its highest cell inhibition in the case of nanoemulsion (F2) where the proliferation percentage was only $21.9 \%$ and $9.2 \%$ against HepG2 and Huh-7 cells, respectively. The same nanoemulsion (F2) also showed the lowest $I_{50}$ values (55.7 and $35.5 \mu \mathrm{g} / \mathrm{ml}$ ) against both HepG2 and Huh-7 cells, respectively, compared to $100 \mu \mathrm{g} / \mathrm{ml}$ for the reference drug Doxorubicin. Flow cytometric analysis also confirmed that nanoemulsion (F2) has the highest apoptotic activity compared to nanoemulsion (F1) and the pure unformulated essential oil. Genetic expressions of pro-apoptotic ( $\mathrm{Bax}$ ) and the anti-apoptotic ( $\mathrm{BCl}-2)$ gene markers evaluation revealed that nanoemulsion (F2) has better activity in upregulating (Bax) and down-regulate (BCl-2) with the highest Bax/Bcl-2 ratio (69) was found against Huh-7 cells. All N. sativa nanoemulsions showed minimal cytotoxicity on the normal WI-38 cell, indicating wide safety margins due to selective properties.
\end{abstract} author(s) and the source, provide a link to the Creative Commons licence, and indicate if changes were made. The images or other third party material in this article are included in the article's Creative Commons licence, unless indicated otherwise in a credit line to the material. If material is not included in the article's Creative Commons licence and your intended use is not permitted by statutory regulation or exceeds the permitted use, you will need to obtain permission directly from the copyright holder. To view a copy of this licence, visit http:// creativecommons.org/licenses/by/4.0/. The Creative Commons Public Domain Dedication waiver (http://creativecommons.org/publi cdomain/zero/1.0/) applies to the data made available in this article, unless otherwise stated in a credit line to the data. 
Conclusion: Overall, the study revealed the potentials of N. sativa essential oil, after formulation in specially tailored nanoemulsion for application as potential adjuvant liver anticancer agent.

Keywords: Apoptosis, Cytotoxicity, Nigella sativa, Essential oil nanoemulsion, HepG2, Huh-7, Liver cancer

\section{Graphical Abstract}

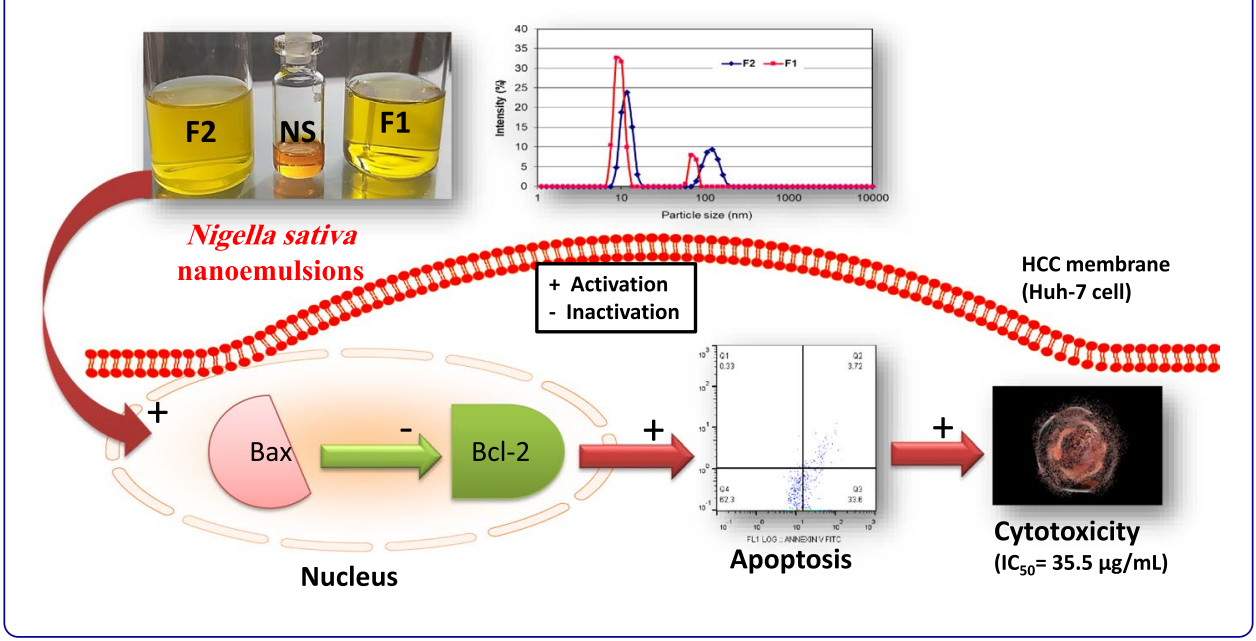

\section{Background}

Liver cancer is prevalent in different parts of the world especially Asia and North Africa. There are different potential causes of this disease including hepatitis (Abutaleb et al. 2021) and excessive alcohol consumption (Thomsen et al. 2020). In addition, mycotoxins and non-alcoholic fatty liver can also be considered as causals of liver cancer (Claeys et al. 2020; Dhamija et al. 2019). Different therapeutic strategies can be used for treatment of liver cancer including hormonal, biochemical, chemotherapeutic and molecular targeted therapies (Shaaban et al. 2014). In addition, early and recent studies showed the promising participation of phytochemicals and herbal medicine in liver cancer therapy strategies (Abdel-Hamid et al. 2018; Fan et al. 2018; Li et al. 2014; Li and Martin 2011). Formulation of phytochemicals in the form of nanoparticles enhances its therapeutic activity due to different factors and mechanisms which are fully discussed (Manivannan et al. 2021; Beg et al. 2020). Polymeric nanoparticles, dendrimers, solid lipid nanoparticles, micelles, etc., are some examples of nanocarriers that are used for delivering phytochemical or synthetic drugs for treatment of liver cancer (Ruman et al. 2020; Sajid et al. 2018). Nanoemulsions are ideal colloidal systems that are used to fabricate and deliver anticancer drugs, including liver cancer, in the form of nanoparticle (Miranda et al. 2021; Groo et al. 2020; Upadhyay et al. 2020). Phytochemicals from aromatic plants like volatile oils (also called essential oils) are also fabricated in nanoemulsion for evaluation against different kinds of cancer cells (Tubtimsri et al. 2021; Salehi et al. 2021).

Among the different phytochemicals and plant extracts, Nigella sativa pressed oil occupies a distinctive place in suppression of different types of cancer cells in vitro (Ahmad et al. 2021; Majdalawieh and Fayyad 2016). That is due to its content of a volatile oil fraction (essential oil) which bears a natural robust anticancer agent namely thymoquinone (TQ) (Schneider-Stock et al. 2014). The role of TQ as liver anticancer agent 
either alone or in combination with other drugs was investigated (Zhang et al. 2021; Bashira et al. 2020; Jehan et al. 2020). Studies on the anticancer activity of N. sativa essential oil (EO) are numerous, however, relevant investigations on its nanoemulsion are generally scarce. For instance, Periasamy et al. (2016) applied the high-energy ultrasonication technique to formulate $N$. sativa EO nanoemulsion for evaluation against breast cancer. No other significant work relevant on $N$. sativa EO nanoemulsion is found.

Based on that, the current study aimed at examining the anticancer activity of $N$. sativa EO and its nanoemulsions on two hepatocellular carcinoma (HCC) cell lines, namely HepG2 and Huh-7. Unlike the previous study of Periasamy et al. (2016), the nanoemulsions in the current study were fabricated using the low-energy spontaneous emulsification technique, which is simpler and does not require sophisticated high-energy equipment. In addition, this technique was elaborated in our study to give high physically stable nanoemulsion that does not separate. Evaluation of the antiproliferative and apoptotic activity of N. sativa EO as well as its nanoemulsions was evaluated in vitro. Different factors affecting the anticancer activity of the EO were studied including the effect of nano-emulsification, the type of surfactant(s) and the type of HCC cells. Safety assessment of the different formulation of $N$. sativa EO was also performed using WI-38 as model for normal cells.

\section{Materials and methods}

\section{Materials}

An authentic cold-pressed oil of Nigella sativa was obtained from the oil expression unit at the National Research Center, Cairo Egypt. Tween 80 (polyoxyethylene sorbitan monooleate) and Tween 20 (polyoxyethylene sorbitan monolaurate) and 3-(4, 5-dimethylthiazol-2-yl)-2,5-diphenyltetrazolium bromide (MTT) were purchased from SigmaAldrich (St. Louis, MO, USA). Roswell Park Memorial Institute (RPMI) 1640 medium, fetal bovine serum (FBS), penicillin/streptomycin (P/S), l-glutamine, trypsin/EDTA, and phosphate-buffered saline (PBS) were obtained from Life Technologies, Gibco (Grand Island, NY, USA). Invitrogen RNA extraction kit, RevertAid First strand cDNA synthesis kit, and annexin V FITC/propidium iodide (PI) kit were obtained from (Thermo Fisher Scientific, USA). MiScript SYBR Green PCR kit was purchased from (Qiagen, Valenica, CA, USA).

\section{Isolation of the essential oil}

Different batches (150 g each) of cold-pressed N. sativa oil were mixed with $1 \mathrm{l}$ of distilled water and subjected to hydro-distillation for $2.5 \mathrm{~h}$ using Clevenger-type apparatus. The condensed essential oil layer was collected from the side arm of the apparatus, dried over anhydrous sodium sulphate and kept in brown glass vial under freezing conditions $\left(-4.0^{\circ} \mathrm{C}\right)$ till utilized in the different formulations and evaluations that is running in this study.

\section{Characterization of the chemical composition of $N$. sativa essential oil}

Gas chromatographic (GC) and gas chromatographic-mass spectroscopic (GC-MS) analysis were used to separate and identify the volatile constituents of $N$. sativa essential oil. 
First, GC analysis: $10 \mu \mathrm{l}$ of the essential oil were dissolved in $1.0 \mathrm{ml}$ diethyl ether, then $2.0 \mu \mathrm{l}$ of this mixture were injected (at a split ratio 10:1) into a Perkin Elmer XL GC equipped with FID. A fused silica capillary column $(60 \mathrm{~m}$ length $\times 0.32 \mathrm{~mm}$ internal diameter $\times 0.25 \mu \mathrm{m}$ film thickness) coated with DB-5 (5\% phenyl, $95 \%$ methyl polysiloxane) was used to separate the different $\mathrm{EO}$ components. The oven temperature was programmed from 50 to $230{ }^{\circ} \mathrm{C}$ at a rate of $3{ }^{\circ} \mathrm{C} / \mathrm{min}$. The injector and detector temperatures were $230{ }^{\circ} \mathrm{C}$ and $250{ }^{\circ} \mathrm{C}$, respectively. Helium was used as carrier gas at a flow rate of $1.0 \mathrm{ml} / \mathrm{min}$. Each essential oil constituent was quantified as peak area percentage relative to the total peak areas, after flame ionization detector (FID). All values of area percent reported in Table 3 were mean of two injections from two different EO extractions \pm SD. The available authentic samples were used to identify the separated volatile constituents of $N$. sativa $\mathrm{EO}$ by matching their retention times.

Second, GC-MS analysis was performed in order to identify the rest of the compounds which have no available authentic sample for their identification. In addition, GC-MS confirms the identity of those compounds which were previously identified by authentic samples in the GC analysis. For that purpose, the same procedure used for GC analysis was repeated using a Hewlett-Packard 5972 GC-MS system equipped with the same column and under the same conditions as used in GC analysis. The ionization voltage was $70 \mathrm{eV}$ and the ion source temperature was $170{ }^{\circ} \mathrm{C}$. The scan range was from 29 to $300 \mathrm{AMU}$ at 2.76 scans per second. Components identification was conducted by automatic matching of their fragmentation patterns $(\mathrm{m} / \mathrm{z})$ with standard components stored in the electronic mass spectral library (NIST: National Institute of Standards and Technology) that was built-in the GC-MS software.

\section{Refractive index measurement}

The refractive index value of $N$. sativa $\mathrm{EO}$ was determined practically on an Abbe ED/60 precision refractometer at $20{ }^{\circ} \mathrm{C}$ (Bellingham and Stanley, Sevenoaks, UK). This value was used for characterization of the particle size of $N$. sativa nanoemulsion using the dynamic laser scattering instrument.

\section{Formulation of nanoemulsion}

Nigella sativa EO was formulated in two different water-based nanoemulsions, denoted as (F1) and (F2), using the low-energy spontaneous emulsification method (Anton and Vandamme 2009). The procedure was modified by the authors to give the desired characteristics of the nanoemulsions according to our previous study (El-Sayed et al. 2017). The ingredients of the two nanoemulsions (F1 and F2) are quantitatively the same, but differ from one another in the composition of the surfactants according to Table 1 . The formulation procedure was started by mixing the surfactant(s) of each formula with propylene glycol (PG) in glass vial followed by mixing using vortex till both mixtures became homogeneous. Then, $N$. sativa $\mathrm{EO}$ was added to each vial containing the surfactant(s)/PG mixture with continuous stirring using vortex to end up with two sets of (surfactants/PG/EO) concentrates. The concentrates were left to equilibrate for $30 \mathrm{~min}$, then each concentrate was titrated dropwise (with continuous magnetic stirring) to adequate amount of distilled water sufficient to make 1.0\% water-based EO nanoemulsions. The process was repeated twice, then all nanoemulsions (F1 and F2 and their 
Table 1 Composition of the different formulae of N. sativa essential oils used for the evaluation of anticancer activity

\begin{tabular}{llll}
\hline Abbreviation & Definition & Composition & Delivery media \\
\hline F0 & Distilled unformulated essential oil & Volatile oil (1.0\%) & DEMSO \\
F1 & Essential oil formulated in nanoemul- & Volatile oil (1.0\%) & Water \\
& sion using binary surfactant mixture & Surfactant mixture ${ }^{\mathrm{a}}(2.0 \%)$ & \\
& & $\mathrm{PG}(0.8 \%)$ & \\
& & Water (96.2\%) & Water \\
F2 & Essential oil formulated in nanoemul- & Volatile oil $\%(1.0 \%)$ & \\
& sion using single surfactant ${ }^{\mathrm{b}}$ & Surfactant ${ }^{\mathrm{b}}(2.0 \%)$ & \\
& & $\mathrm{PG}(0.8 \%)$ & \\
& & Water $(96.2 \%)$ & \\
\hline
\end{tabular}

$P G$ propylene glycol

${ }^{a}$ Tween 80/Tween 20 (2:1 weight ratio)

b Tween 80 only

duplicates) were kept in dark glass bottles with caps and left for $48 \mathrm{~h}$ to equilibrate at $25^{\circ} \mathrm{C}$. After that the samples were subjected to physical characterization and for biological evaluations.

\section{Characterization of nanoemulsions}

Appearance

Glass vials containing the different nanoemulsions were examined visually against bright light to check their opacity or translucency. The UV-Vis absorption values of nanoemulsions were also evaluated spectrophotometrically using Shimadzu (UV-160 1PC spectrophotometer, Japan) at wave length $\lambda=600 \mathrm{~nm}$ to establish a quantitative measure for the visual examination of transparency of the samples. The absorption values $(A)$ are an average of two measurements from two different formulations.

\section{Transmission electron microscopy (TEM)}

Particle morphology of the formulated nanoemulsions was examined using TEM (Philips CM-10 FEI, In., Hillsboro, OR, USA). Fifty microliter of each nanoemulsion was dropped into Formvar-coated copper grids and left to dry. Then the samples were stained using $2 \% \mathrm{w} / \mathrm{v}$ uranyl acetate as a negative staining agent. Image capture and analysis was done using Digital Micrograph and Soft Imaging Viewer software (Electron Microscope Unite services), NRC, Egypt.

\section{Particle sizing}

The particle size of the nanoemulsions was measured using the dynamic light scattering instrument Zetasizer (Nano-ZS model ZEN3600, Nanoseries, Malvern Instruments, UK). The refractive index value of the dispersed phase ( $N$. sativa EO) used for measurements was 1.46 as determined practically, and that of the continuous phase (water) was 1.33 . Measurements were done at $20{ }^{\circ} \mathrm{C}$ unless otherwise is specified, with a fixed angle of $173^{\circ}$. Before measurement, all samples were filtered through a $0.20-\mu \mathrm{m}$ single use syringe filter unit (Minisart ${ }^{\circledR}$, Sartoius Stedium Biotech GmbH Germany) to remove impurities. Each sample was diluted before measurement with distilled water to only $0.05 \%$ to prevent multiple scattering. The measurements are based on the Brownian 
motion of the hydrated particles, thus it provides information on the hydrodynamic diameter $(\mathrm{nm})$ of the EO particles. Sizes quoted are the $z$-average mean of the EO droplet's hydrodynamic diameter $(\mathrm{nm})$ obtained from six measurements for each sample (2 duplicate $\times 3$ measurements each). The particle size distributions curves (Fig. 3) are plotted from dynamic light scattering data as average of duplicate samples.

\section{Storage stability}

Small portion $(10 \mathrm{ml})$ of each of the two freshly formulated nanoemulsions (F1 and F2) was spared in capped transparent glass vials and left to stand undisturbed on the bench at room temperature $\left(25{ }^{\circ} \mathrm{C} \pm 2\right)$ for 6 months. During this period, the samples were regularly inspected visually to detect any change in nanoemulsion appearance such as cloudiness, oil separation or creaming.

\section{Hepatic cancer cell cultivation}

The hepatic cancerous HepG2 and Huh-7 cell lines as well as the normal WI-38 cell line were purchased from American Type Culture Collection (ATCC) supplied from VCSERA and cultivated in RPMI 1640 medium (Gibco) supplemented with 10\% heatinactivated fetal bovine serum (Gibco), $100 \mathrm{U} / \mathrm{ml}$ streptomycin, and $100 \mathrm{U} / \mathrm{ml}$ penicillin at $37^{\circ} \mathrm{C}$ in a humidified $5 \% \mathrm{CO}_{2}$ atmosphere.

\section{Cell proliferation assay}

Hepatic cancerous HepG2, Huh-7, and normal WI-38 cells were seeded in 96-well plates at a density of $1 \times 10^{4}$ cells/well and incubated for $24 \mathrm{~h}$, then they were subsequently treated with $0,20,40,60,80$, and $100 \mu \mathrm{g} / \mathrm{ml}$ of F0, F1, and F2 for $24 \mathrm{~h}, 48 \mathrm{~h}$ and $72 \mathrm{~h}$ incubation period. On the other hand, control cells were treated with PBS up on medium. After that, the cells were incubated with $1 \mathrm{mg} / \mathrm{ml}$ of MTT reagent at $37^{\circ} \mathrm{C}$ for $4 \mathrm{~h}$ and then it was discarded. The formed formazan crystals were dissolved using $100 \mathrm{ml}$ of DMSO, followed by incubation and shaking. Finally, colorimetric analysis using a multi-plate reader was measured at $540 \mathrm{~nm}$. The cell viability (\%) was calculated and compared with control.

\section{Measurement of the half-inhibitory concentration}

The half-maximal inhibitory concentrations $\left(\mathrm{IC}_{50}\right)$ values, the concentrations inhibit $50 \%$ of cell viabilities, were obtained by plotting the percentages of cell viabilities versus the concentrations of the sample using polynomial concentration-response curve fitting models (OriginPro 8 software). Finally, the fold changes of nano-formulations versus their free pure compounds and the positive control (Doxorubicin; DOX) were measured for all cells.

\section{Nanoparticles internalization}

To track nanoparticles internalization (diffusion) in the HepG2, Huh-7, and WI-38 cells, we used EO nanoemulsions (F1, F2) labeled with Alexa Flour 488 dye followed by tracking the fluorescence of the stable dye throughout the cancer cells. HepG2, Huh-7, and WI-38 cells were treated with the $\mathrm{IC}_{50}$ of the F1 and F2 and cultivated for 2 and $4 \mathrm{~h}$ incubation. $1 \times 10^{5}$ cells were seeded in 24 -well plate and left overnight for adherence. On the 
second day, cells were washed using two steps; (1) Cold PBS $1 \times$ wash (twice) to get rid of excess fluorescence on the media, and (2) cold acidic wash of $0.05 \mathrm{M}$ glycine $+0.15 \mathrm{M}$ $\mathrm{NaCl}$ (twice) then cold PBS $1 \times$ wash to get rid of the cell membrane-attached nanoparticles, which were not internalized. Eventually, flow cytometric analysis was performed using (Beckman Coulter Instrument, USA).

\section{Flow cytometry-based apoptosis assay}

Flow cytometry was used to detect the early and late apoptotic cell distributions and healthy populations. Hepatic cancerous HepG2, Huh-7, and normal WI-38 cells were seeded at a density of $1 \times 10^{6}$ cells/ T25-flask and incubated for $24 \mathrm{~h}$. Cells were treated with the $\mathrm{IC}_{50}$ of the F0, F1, and F2 shown in Table 1 and cultivated for $24 \mathrm{~h}$ incubation. After a day, all cells were stained with annexin V FITC and propidium iodide (PI) (Thermo Scientific). The apoptosis of the treated and untreated cells was analyzed by flow cytometer (Beckman Coulter Instrument, USA). 25,000 events were recorded per each sample. Apoptotic distributions were measured using flow cytometry and analyzed using its software.

\section{Measurements of ROS markers}

\section{Nitric oxide (NO)}

The cells were cultured in 96-well plates at a density of $1 \times 10^{4}$ cells/well. In the second day, the $\mathrm{IC}_{50}$ dosages of the proposed treatments were added in the media. Nitrate reductase was firstly used to convert nitrate to nitrite. Then, Griess reagent was used to convert nitrite to a deep purple azo compound. The amount of the azo chromophore accurately reflected NO amount in the samples. Finally, optical density was measured at OD $540 \mathrm{~nm}$ using the micro-plate reader (BMG Labtech, Germany).

\section{Malondialdehyde (MDA)}

The cells were cultured in 96-well plates at a density of $1 \times 10^{4}$ cells/well. On the second day, the $\mathrm{IC}_{50}$ dosages of the proposed treatments were added in the media. The free MDA present in the sample was reacted with thiobarbituric acid (TBA) to generate MDA-TBA adduct, which can be easily quantified colorimetrically at OD $532 \mathrm{~nm}$ using the micro-plate reader (BMG Labtech, Germany).

\section{Quantitative reverse transcription-polymerase chain reaction (qRTPCR)}

Total RNA extraction: total RNA was extracted from HepG2, Huh-7, and WI-38 cells at a density of $1 \times 10^{6}$ cells/ T25-flask with the $\mathrm{IC}_{50}$ dosage of the proposed treatments using the Invitrogen RNA Purification kit (Thermo Fisher) according to the manufacturer's protocol. Cells were applied with the $\mathrm{IC}_{50}$ dosage of the proposed treatments and incubated for $24 \mathrm{~h}$. The concentration and the purity of RNA were assessed by Nanodrop Technologies at 260/280 ratio.

Conversion of RNA to cDNA: first-strand cDNA was synthesized with $1 \mu \mathrm{g}$ of total RNA using a RevertAid First strand cDNA synthesis kit (Thermo Fisher Scientific, USA) in accordance with the manufacturer's instructions. These samples were subsequently frozen at a temperature of $-80^{\circ} \mathrm{C}$ until use for determination of the expression levels of $\mathrm{Bax}$ and $\mathrm{Bcl}-2$ genes using real-time PCR. 
Real-time PCR reactions: quantitative real-time PCR was performed on DT-lite RealTime PCR System (English/Russian system) using the MiScript SYBR Green PCR kit which was purchased from (Qiagen, Valenica, CA, USA), in addition to the forward and reverse primers for each gene. The nucleic acid sequences of the forward (F) and reverse (R) primers of Bax and Bcl-2 genes compared to GAPDH as a housekeeping gene are illustrated in Table 2.

Real-time PCR mixture consisted of $10 \mu \mathrm{l}$ of SYBR PCR Master Mix, $1 \mu \mathrm{l}$ of each primer $(400 \mathrm{nM}), 1 \mu \mathrm{lDNA}$, and $7 \mu \mathrm{l}$ Rnase-free water in a total volume of $20 \mu \mathrm{l}$. Amplification conditions and cycle counts were a temperature of $95^{\circ} \mathrm{C}$ for $15 \mathrm{~min}$ for the initial activation, followed by 40 cycles of denaturation at $95^{\circ} \mathrm{C}$ for $30 \mathrm{~s}$, annealing at $55^{\circ} \mathrm{C}$ for $30 \mathrm{~s}$, and elongation at $72{ }^{\circ} \mathrm{C}$ for $30 \mathrm{~s}$. Melting curves were performed after real-time PCR to demonstrate the specific amplification of single products of interest. A standard curve assay was performed to determine the amplification efficiency of the primers used. Relative fold changes in the expression of target genes were accomplished using GAPDH gene as an internal control to normalize the level of target gene expression. Logarithmic transformation was performed on fold-change values before being statistically analyzed, using the fold-change values of three replicates for the two measured genes.

\section{Statistical analysis}

Results of the biological activity (represented as graphs) were conducted using the oneway ANOVA (SPSS program, version 21). Bars in all graphs were represented as mean of 3 different experiments $(\mathrm{n}=3) \pm$ standard deviation (SD).

\section{Results and discussion}

\section{Characterization of $N$. sativa essential oil}

Table 3 shows the chemical composition of $N$. sativa EO which is evaluated in vitro as a natural plant extract against some HCC cells. Three major volatile components represented $84.0 \%$ of the total identified compounds were reported. These components include $\alpha$-thujene (12.8\%), p-cymene (40.0\%) and thymoquinone (TQ, 31.2\%). In addition, there are some other identified components which are less abundant compared to the three major ones (Table 3). In general, the identified components are considered to be qualitatively classical and conforming with previous studies (Edris et al. 2018; Shaaban et al. 2015) with no new components to report. However, from the quantitative view point, there is a difference in the percentage of these components from those reported in the previous studies. For instance, the content of the three major

Table 2 Primer sequences

\begin{tabular}{|c|c|c|}
\hline Gene & Primer sequence & \\
\hline \multirow[t]{2}{*}{$\mathrm{BCL}-2$} & $\mathrm{~F}$ & 5'-CTGCACCTGACGCCCTTCACC-3' \\
\hline & $\mathrm{R}$ & 5'-CACATGACCCCACCGAACTCAAAGA-3' \\
\hline \multirow[t]{2}{*}{ Bax } & $\mathrm{F}$ & 5'-ATGGCTTCTATGAGGCTGAG-3' \\
\hline & $\mathrm{R}$ & 5'-CGGCCCCAGTTGAAGTTG-3' \\
\hline \multirow[t]{2}{*}{ GAPDH } & $\mathrm{F}$ & 5'-GTCTCCTCTGACTTCAACAGCG-3' \\
\hline & $\mathrm{R}$ & 5'-ACCACCCTGTTGCTGTAGCCAA-3' \\
\hline
\end{tabular}

$F$ forward primer, $R$ reverse primer 
Table 3 Chemical composition of N. sativa essential oil after gas chromatography (GC) and gas chromatography-mass spectroscopic (GC-MS) analysis

\begin{tabular}{ll}
\hline Identified compounds & $\begin{array}{l}\text { Peak area } \\
\text { (\%) (from GC } \\
\text { analysis) }\end{array}$ \\
\hline Trans-a-thujene $^{\mathrm{a}}$ & $12.8 \pm 0.8$ \\
a-pinene $^{\mathrm{b}}$ & $2.6 \pm 0.1$ \\
Sabinene $^{b}$ & $1.0 \pm 0.05$ \\
B-pinene $^{\text {b }}$ & $2.6 \pm 0.1$ \\
p-cymene $^{\text {b }}$ & $40.0 \pm 1.0$ \\
Cis-4-methoxythujan $^{\mathrm{a}}$ & $0.5 \pm 0.005$ \\
Trans-4-methoxythujan $^{\mathrm{a}}$ & $3.2 \pm 0.05$ \\
Thymoquinone $^{\mathrm{b}}$ & $31.2 \pm 2.4$ \\
Carvacrol $^{b}$ & $0.9 \pm 0.07$ \\
Longifolene $^{\mathrm{a}}$ & $0.9 \pm 0.09$ \\
Total identified $^{\text {a }}$ & 95.7 \\
\hline
\end{tabular}

${ }^{\text {a }}$ Compounds identified by GC-MS

${ }^{a b}$ Compounds identified by GC-MS and confirmed with authentic samples injection

constituents $\alpha$-thujene, p-cymene and TQ were previously found to be $0.7 \%, 20.0 \%$ and $68.1 \%$, respectively (Hamed et al. 2017). Such significant difference in the composition of the main constituents of $N$. sativa EO is commonly experienced by different researchers. That is due to some factors related to genetic diversity of the seeds and/or the climatic variations from one geographical location to another. Generally, the content of TQ in the essential oil participate significantly to the anticancer activity of $N$. sativa EO due to the role of this component in apoptosis, as previously reviewed in "Background" section.

\section{Formulation, characterization and stability of the nanoemulsions}

The EO of $N$. sativa was formulated in two water-based nanoemulsions (F1 and F2) using the low-energy spontaneous emulsification method. This method is simple and can be scaled up easily to the industrial level without obligation to use expensive highenergy equipment. Nanoemulsions (F1 and F2) differ from one another in the composition of the surfactants (Table 1). Nanoemulsion (F1) was fabricated using a mixture of surfactants including Tween 80 plus Tween 20 at (2:1) weight ratio. This mixture was selected based on the fact that combination of surfactants can affect better emulsification, stability and smaller particle size compared to single surfactant (Galindo-Alvarez et al. 2011). The ratio of (2:1) was optimized after different trials by the authors aiming to find the most appropriate weight fractions that give smaller and stable nanoparticles.

On the other hand, nanoemulsion (F2) was fabricated using a single surfactant (Tween 80), which is widely used as drug formulation vehicle for anticancer drugs like the taxane anticancer agents that include paclitaxel and docetaxel (Tije et al. 2003).

Figures 1, 2 and 3 show the different approaches used to characterize the formulated nanoemulsions regarding their appearance, particles morphology and particle size distribution.

Figure 1 indicates that the appearance of both formulae is transparent or translucent but not cloudy, giving a preliminary impression of small nanoparticles that do not scatter light. The nanoemulsion formulated using a mixture of surfactants (F1) 


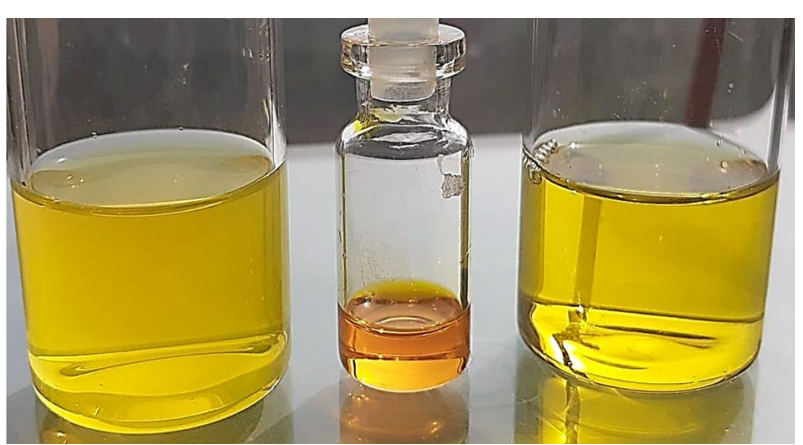

Fig. 1 Appearance of the water-based N. sativa essential oil nanoemulsions (after $48 \mathrm{~h}$ equilibration at $25^{\circ} \mathrm{C}$ ). Vials from left: nanoemulsion (F2), middle: pure unformulated essential oil, right: nanoemulsion (F1)
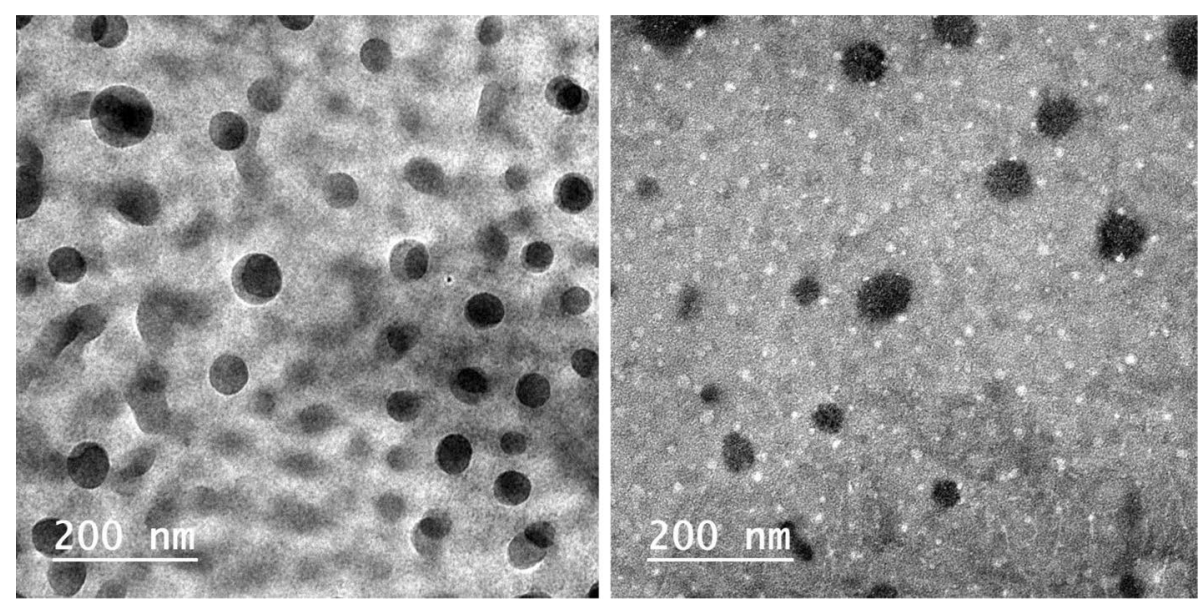

Fig. 2 TEM photos of N. sativa essential oil nanoemulsions after negative staining. Left nanoemulsion (F1), right nanoemulsion (F2)

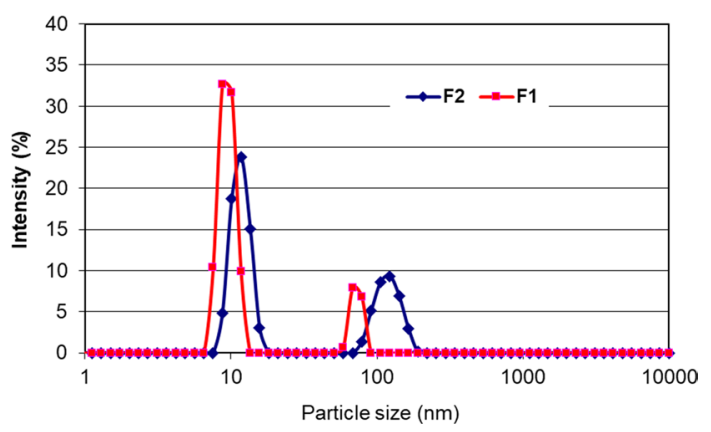

Fig. 3 Particle size distribution of N. sativa nanoemulsions (F1) and (F2) evaluated using dynamic laser scattering

looked transparent (Fig. 1, right) while that formulated using single surfactant (F2) appeared translucent (Fig. 1, left). That indicates more light scattering and relatively larger particles compared to (F1). UV-vis absorption at $600 \mathrm{~nm}$ confirmed the visual 
appearance where the absorption value of (F1) was 0.023 which is lower than that of (F2) which recorded 0.194. These spectroscopic data indicate two nanoemulsions in which the $\mathrm{EO}$ is dispersed homogenous as nanoparticles in the approximate range of $10-100 \mathrm{~nm}$, as predicted from the low visible light absorption and the minimally scatter light.

Figure 2 shows the particles' morphology of (F1) and (F2) using the negative staining transmission electron microscope (TEM). The figure indicates that both nanoemulsions have spherical-shaped particles which have a diameter in the targeted nano-size range $(\sim 100 \mathrm{~nm}$, Fig. 2). However, TEM analysis just gave an approximation on the particle size of the nanoemulsion. That is because it is hard to find a field that covers all particle size populations in the nanoemulsion due to the low oil droplets concentration (1.0\%). In addition, artifact formation due to negative staining of the nanoemulsions and the high vacuum of operation may also alter the real size of the particles.

Therefore, for more comprehensive data about the particle size diameter of both nanoemulsions, dynamic light scattering analysis was conducted (Fig. 3). The figure shows that nanoemulsion (F1) has two particles populations, the first has droplets of $9.4 \mathrm{~nm}$ (intensity $84.6 \%$ ) and the second has droplets of $72.3 \mathrm{~nm}$ (intensity $15.4 \%$ ). Similarly, nanoemulsion (F2) also showed two relatively larger particles populations, the first is $11.6 \mathrm{~nm}(65.5 \%)$ and the second is $119.7 \mathrm{~nm}$ (34.5\%). These data correlated well with the appearance of both nanoemulsions illustrated in Fig. 1, especially (F2) which appeared translucent with more light scattering due to the second population of particles that have $119.7 \mathrm{~nm}$.

From the above-mentioned findings (Figs. 1, 2 and 3), we can confirm the formulation of N. sativa EO in two nanoemulsions (F1 and F2) which differ slightly from one another in their average particle size due to surfactants' composition.

These nanoemulsions were also found to be physically stable against gravitational separation after a 6-month storage period at $25^{\circ} \mathrm{C}$. Visual observation of the nanoemulsions at regular intervals during that storage period did not detect any opacity, oil separation or creaming, which indicate high physical stability of both formulae. What was remarkable is that nanoemulsion (F2) which looked translucent right after formulation (Fig. 1, left) became more transparent after storage. The measured UV-vis absorbance at $\lambda 600 \mathrm{~nm}$ confirmed that visual observation in which the value changed from 0.194 right after formulation (zero time) to become 0.02 after 6-month storage. This indicates that the particles of the formulated nanoemulsions are dynamic and tend to change their size continuously to the smaller during storage till they reach a final equilibrium state. This is considered to be an advantage of the formulated nanoemulsions, which proved to be both thermodynamically and kinetically stable. That is due to the meticulous choice of the ingredients and their ratios in both nanoemulsions (Table 1).

After formulation, characterization and stability evaluation of the nanoemulsions, all formulation including the pure distilled unformulated EO (F0) were subjected to the different anticancer evaluations as will be tackled in the next passages. 


\section{Assessment of cytotoxicity of $N$. sativa essential oil and its nanoemulsions}

The cytotoxic effect of the distilled $N$. sativa EO (F0) as well as its two nanoemulsions (F1 and F2) was evaluated against some hepatocellular carcinoma (HCC) cell lines, namely, HepG2 and Huh-7 cells. These cell lines are commonly used as models for in vitro evaluation of cytotoxicity of chemotherapeutic drugs which is used in advanced liver cancer (Dubbelboer et al. 2019). The cytotoxic effect of the different $N$. sativa EO formulations was evaluated in two terms, cell proliferation percentage and $\mathrm{IC}_{50}$ values.

\section{Cytotoxicity in terms of cell proliferation percentage}

In this assay, the percentage of $\mathrm{HCC}$ cells which remained alive after treatment with gradient doses $(20-100 \mu \mathrm{g} / \mathrm{ml})$ of each $N$. sativa EO formulation was evaluated and illustrated in Fig. 4. The results revealed that there is a dose-dependent decrease in HCC cell proliferation percentage upon treatment with the different formulations after $24 \mathrm{~h}, 48 \mathrm{~h}$, and $72 \mathrm{~h}$ incubation period.

In detail, the unformulated distilled EO of $N$. sativa (F0) inhibited HCC cell proliferation to $47.2 \%$ and $42.1 \%$ for HepG2 and Huh-7 cells, respectively, after 24-h treatment with $100 \mu \mathrm{g} \mathrm{EO} / \mathrm{ml}$ (Fig. 4a). This means that the inactivation of both HCC cells

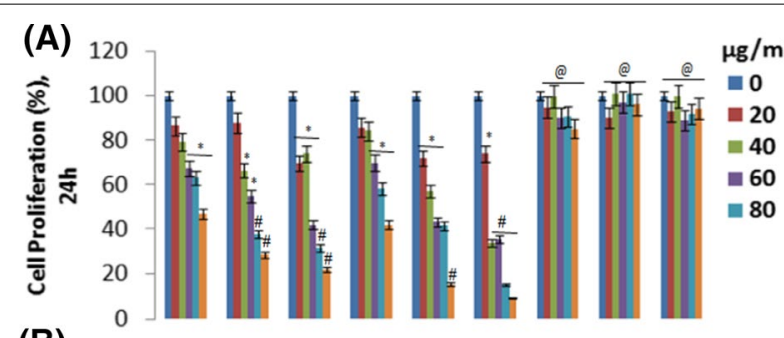

(B) 120

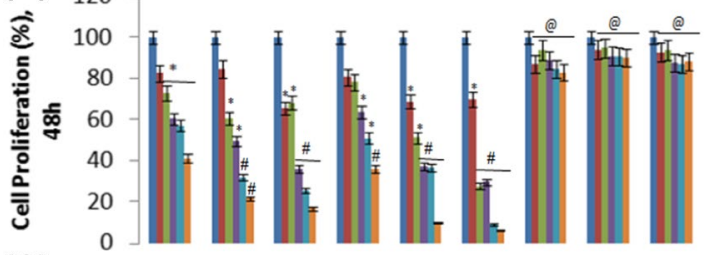

(C) 120

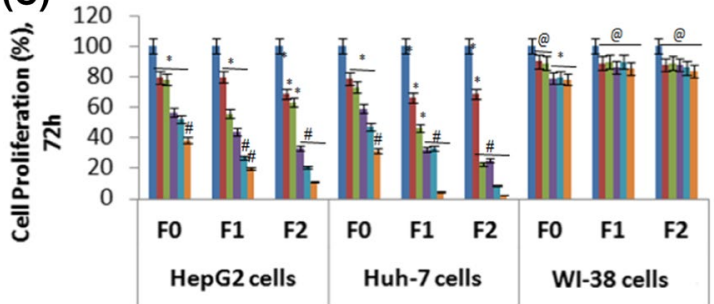

Fig. 4 Cytotoxicity of N. sativa essential oil (F0) and its nanoemulsions (F1 and F2) against hepatocellular carcinoma cell lines (HepG2 and Huh-7) in comparison to normal WI-38 cells. Cells were incubated with these formulas for $24 \mathrm{~h} \mathrm{(a)}, 48 \mathrm{~h}(\mathbf{b})$, and $72 \mathrm{~h}$ (c). Doses are expressed in $\mu \mathrm{g} / \mathrm{ml}$. Bars represent average of 3 replicates \pm SD. *Statistically significant decrease of treated cancer cells compared to control $(P<0.05)$. \#High statistically significant decrease of treated cancer cells compared to control $(P<0.01)$. ${ }^{@ N o n-s i g n i f i c a n t ~}$ change of treated WI-38 cells compared to control $(P<0.05)$ 
reached $52.8 \%$ and $57.9 \%$, respectively, after treatment with the highest tested dose of (F0). Figure $4 \mathrm{~b}$, c shows the same trend of cancer cell inhibition after incubation for $48 \mathrm{~h}$ and $72 \mathrm{~h}$, recording higher inhibition values compared to $24 \mathrm{~h}$ incubation.

The antiproliferative activity of (F0) is likely to be attributed to the presence of thymoquinone (TQ, 31.0\%) among the chemical constituents of N. sativa EO (Table 3). This compound per se is an active anticancer agent which manifested its own antiproliferative and protective activity against different cancer cell models (Ha et al. 2020; Bhattacharjee et al. 2020), including HCC (Bimonte et al. 2019). Generally, TQ has been found to modulate a battery of signaling pathways that prevents tumor progression (Zhang et al. 2020; Afrose et al. 2020; Fatfat et al. 2019; Schneider-Stock et al. 2014). In more specific discussion regarding HCC, an earlier study by Ashour et al. (2014) indicated that TQ can cause G2M cell cycle arrest and inhibit expression of NF-jB and suppressed IL-8 and its receptors, beside upregulation of TRAIL death receptors. More recently, Aslan et al. (2021) added that TQ showed antiproliferative activity against HepG2 cells by inducing ceramide accumulation and ER stress in conjunction with decreasing S1P, C1P and NF- $\mathrm{KB}$ mediated cell survival. All these effects can promote HepG2 cancer cell death by triggering apoptosis. In addition, TQ can sensitize HepG2 cells to TRAIL-induced apoptosis via oxidative DNA damage and by inducing the death receptor pathway (Zhang et al. 2021).

Based on the above mentioned, we should link the antiproliferative activity of the EO (F0) to its content of TQ which was found to be only $31.2 \%$ of the constituents of $N$. sativa EO (Table 3). This percentage is considered to be low compared with other values (56.2\% and $68.1 \%$ ) which were previously reported by our group (Hamed et al. 2017) using different seeds of $N$. sativa. That illustrates the importance of screening for the seeds that bear high content of TQ. In addition, the method of extracting the EO from the seeds also has significant effect on the content of TQ in the oil (Edris et al. 2018; Edris 2010).

So, we preliminarily presume that the previously illustrated example of EO with high TQ content (68.1\%, Hamed et al. 2017) would have shown about double the antiproliferative activity compared to the EO evaluated in the current study which contained only $31.2 \%$ TQ. However, we should be careful regarding this statement because the relationship between TQ content in EO and antiproliferative activity may not be linear as we presume. Therefore, it will be interesting in the future to examine this statement using different seeds that bear variable percentages of TQ among their EO. In this regard, seeds from Nigella hispanica are recommended as a negative control for comparison, because its EO has $0.0 \%$ TQ (Kokoska et al. 2012), with no other antiproliferative active ingredients in that EO.

Due to the diversity of volatile components in the EO of N. sativa (Table 3), it could be possible that other components participate together with TQ in the overall antiproliferative activity of the EO. For instance, the EO contains considerable amounts of terpenes like p-cymene $(40.0 \%)$ and trans-a-thujene $(12.8 \%)$ in combination with other minor components (Table 3). To our knowledge, we did not find reports which proclaim cytotoxic effect of each individual components of these terpenes. However, Silva et al. (2020) emphasize on the important role of these terpenic compounds (all together, without TQ) on the overall cytotoxic activity of EO of $N$. sativa against MCF-7 cells. 
One of the interesting findings that we can extract from Fig. 4 is that Huh-7 cells are more sensitive to the EO of N. sativa (F0) than HepG2 in all time incubation periods. The same observation was previously reported in another study (Ashour et al. 2014) where pure TQ was used as an antiproliferative agent. The reason for that phenomena is not known so far, but we assume that it is related to the receptors on the surface of the cell wall of both HepG2 and Huh-7 cells. It worth indicating that one of the main differences between these cells is on p53 expression. HepG2 cells carry wild-type p53, whereas Huh-7 cells have null and point mutations at p53 codon 220, respectively.

\section{Effect of nanoemulsions on the cell antiproliferation percentage}

The EO of N. sativa was formulated in two water-based nanoemulsion formulae (F1 and F2) which differ from one another in the composition of the surfactants (Table 1). The structure of the nanoemulsion in the current study is typically composed of a continuous pool of water which bears nanoparticle composed of spherical layers of surfactant(s) encapsulating the EO of $N$. sativa in its inner lipophilic core. This nanoemulsion is described as one of the phytomedicine-based delivery systems which is used for therapeutic strategies in liver cancer (Kumar et al. 2020). It is also suitable for oral or parenteral administration routs due to its water-based nature.

Figure 4a shows that both nanoemulsion systems (F1 and F2) inhibited the proliferative activity of HCC cells more than the non-formulated EO (F0) after 24-h incubation period. For instance, nanoemulsion (F1), showed inhibition in proliferative activity to become only $28.7 \%$ and $15.5 \%$ against HepG2 and Huh-7 cells, respectively. Interestingly, nanoemulsion (F2) showed the same trend with even more proliferation inhibition activity which was further dropped to $21.9 \%$ and $9.2 \%$ against HepG2 and Huh-7 cells, respectively. Figure $4 \mathrm{~b}, \mathrm{c}$ shows higher inhibition values compared to $24 \mathrm{~h}$ incubation. From these data it is clear that the activity of $N$. sativa EO (F0) is greatly enhanced upon formulation in nanoemulsion. That, can be attributed to the better diffusion of nanoparticles into the cancer cells. That was verified by labeling nanoemulsions (F1 and F2) with Alexa Flour 488 dye followed by tracking the fluorescence of the stable dye throughout the cancer cells, as will be illustrated in details later under particles internalization section.

Figure 4 also indicates that nanoemulsion (F2) has better inhibition of HCC cells proliferation than (F1). That confirms clearly the effect of nanocarrier material, i.e., the surfactant, on the activity of cancer drug models formulated in nanoemulsion. So far, we do not have enough clear evidence to justify why nanocarrier made of $100 \%$ Tween 80 , as nanoemulsion F2, gave better inhibition in proliferation compared to (F1) which is made of a mixture of Tween 80 (66.6\%) and Tween $20(33.3 \%)$. However, that can be due to the inherent cytotoxic effect of Tween 80 on some cancer cells (Kubis et al. 1979; Kay 1965). It could be also be due to the difference in the carbon chain length of the fatty acid moiety of both surfactant nanocarriers which host the EO in the inner core. Tween 80 has 18 carbon atoms while Tween 20 has only 12 carbon atoms. This difference in the volume faction of the inner fatty acid part of the nanocarrier may differentially affect the interaction and hence the release of the EO to HCC cells. More work is still needed to justify this issue on an evidence-based background. 


\section{Cytotoxicity in terms of $\mathrm{IC}_{50}$}

$\mathrm{IC}_{50}$ is another manifestation of cytotoxicity of certain drug model against cancer cells. It is defined as the concentration of the drug necessary to kill half of the cancerous cells, therefore, the smaller the value of $\mathrm{IC}_{50}$ the more cytotoxic is the drug. Results in Table 4 show that the different formulations of $N$. sativa EO (F0, F1 and F2) have lower $\mathrm{IC}_{50}$ values compared to the reference drug doxorubicin $(100 \mu \mathrm{g} / \mathrm{ml})$. The lowest $\mathrm{IC}_{50}$ compared to that of doxorubicin was found for nanoemulsion (F2) against Huh-7 cells.

The ratio of $\mathrm{IC}_{50}$ of the drug relative to that of F0, F1 and F2 is denoted as fold change (a), which shows the magnitude of enhanced activity of the EO formulations relative to Doxorubicin (Table 4). This value is always $>1$ indicating that all formulations are more cytotoxic than the reference drug, especially nanoemulsion (F2) against Huh-7 cells where the fold change is 2.81 .

From Table 4 it is also evident that the nanoemulsions (F1 and F2) have lower $\mathrm{IC}_{50}$ value, i.e., higher cytotoxicity, relative to (F0) after $24 \mathrm{~h}$ incubation period. That confirms the potentials of nanoparticles for enhancing the cytotoxicity and inhibitory activity of $N$. sativa EO. The ratio of $\mathrm{IC}_{50}$ of (F0) relative to that (F1) and (F2) is denoted as fold change (b), which was also always $>1$, indicating higher $\mathrm{IC}_{50}$ values for (F0). The fold change (b) reached its highest value for nanoemulsion (F2) against Huh-7 (2.54), indicating that (F0) is much lower in cytotoxicity compared to nanoemulsion (F2). Table 4 also shows the $\mathrm{IC}_{50}$ of all formulations and their fold change after $48 \mathrm{~h}$ and $72 \mathrm{~h}$, where the highest fold change after $72 \mathrm{~h}$ was found for F2 against Huh-7 cells (3.57).

Comparing our results with previous investigations, we found that the $\mathrm{IC}_{50}$ of pure TQ against HepG2 was $6.16 \mu \mathrm{g} / \mathrm{ml}$ (El-Najjar et al. 2010; Fröhlich et al. 2017). In addition, a plant extract isolated from Indigofera zollingeriana also showed low $\mathrm{IC}_{50}$ values against HepG2 (6.8 ug/ml) and Huh-7 cells (8.7 ug/ml) (Vo et al. 2020). However, we can justify their lower $\mathrm{IC}_{50}$ values compared to ours based on the prolonged contact time between the HCC cells and the plant extract, which was double ( $48 \mathrm{~h}$ ) the

Table $4 \quad I_{50}$ values of N. sativa essential oil (F0) and its nanoemulsions (F1 and F2) against HepG2 and Huh-7 hepatocellular carcinoma cells at different incubation time

\begin{tabular}{|c|c|c|c|c|c|c|c|c|c|}
\hline \multirow[t]{2}{*}{ Incubation time } & \multirow[t]{2}{*}{$\mathrm{IC}_{50}$ and fold change } & \multicolumn{4}{|c|}{ HepG2 } & \multicolumn{4}{|c|}{ Huh-7 } \\
\hline & & $\mathrm{RD}^{\mathrm{a}}$ & Fo & $\mathrm{F} 1$ & F2 & RD & Fo & $\mathrm{F} 1$ & F2 \\
\hline \multirow[t]{3}{*}{$24 \mathrm{~h}$} & $\mid C_{50}(\mu \mathrm{g} / \mathrm{ml})$ & 100.0 & 98.39 & 65.27 & 55.74 & 100.0 & 90.44 & 52.38 & 35.5 \\
\hline & Fold change (a) & - & 1.01 & 1.53 & 1.79 & - & 1.10 & 1.90 & 2.81 \\
\hline & Fold change (b) & - & 1.00 & 1.5 & 1.76 & - & 1.00 & 1.72 & 2.54 \\
\hline \multirow[t]{3}{*}{$48 \mathrm{~h}$} & $\mathrm{IC}_{50}(\mathrm{\mu g} / \mathrm{ml})$ & 97.65 & 73.97 & 60.96 & 54.34 & 95.94 & 76.00 & 51.78 & 35.33 \\
\hline & Fold change (a) & - & 1.00 & 1.21 & 1.36 & - & 1.00 & 1.47 & 2.15 \\
\hline & Fold change (b) & - & 1.32 & 1.60 & 1.80 & - & 1.26 & 1.85 & 2.72 \\
\hline \multirow[t]{3}{*}{$72 \mathrm{~h}$} & $\mathrm{IC}_{50}(\mu \mathrm{g} / \mathrm{ml})$ & 92.61 & 66.23 & 49.26 & 45.10 & 89.21 & 45.10 & 41.14 & 25.00 \\
\hline & Fold change (a) & - & 1.00 & 1.34 & 1.47 & - & 1.47 & 1.57 & 2.59 \\
\hline & Fold change (b) & - & 1.40 & 1.88 & 2.05 & - & 1.38 & 2.17 & 3.57 \\
\hline
\end{tabular}

Fold change (a): (IC 50 RD/IC 50 F0, F1 or F2)

Fold change (b): (IC $\mathrm{I}_{50} \mathrm{~F} 0 / \mathrm{IC} \mathrm{L}_{50} \mathrm{~F} 1$ or $\left.\mathrm{F} 2\right)$

$R D$ reference drug (Doxorubicin) 
contact time that we applied $(24 \mathrm{~h})$ in the current study. One should also bear in mind that the widespread cultivation of N. sativa and its abundance all over the world make it more available for practical pharmaceutical applications on large scale.

\section{Nanoparticles internalization}

The internalization (diffusion) of EO nanoparticles of F1 and F2 inside the HepG2 (Fig. 5a), Huh-7 (Fig. 5b), and WI-38 (Fig. 5c) cells was tracked after 2 and $4 \mathrm{~h}$ incubation using flow cytometry. We found that the endocytosis inside the Huh-7 cells was higher than HepG2 cells for both formulations F1 and F2. Formula F2 recorded higher entrapment capacity inside the HepG2 cancerous cells at $4 \mathrm{~h}$ (32) compared to the control (4.32). Intriguingly, F2 recorded the highest entrapment capacity inside the Huh-7 cancerous cells at $4 \mathrm{~h}$ (33.6) compared to the control (3.27). Figure 5c illustrates the effect of F1 and F2 on normal cells, showing that there was a slight endocytosis occurred reaching the maximum at $4 \mathrm{~h}$ using F2 (10.2) compared the control (5.47).

\section{Apoptosis}

After studying the cytotoxic effect of $N$. Sativa EO and its two nanoemulsions against HCC cells, this section investigates the mechanistic approach of killing cancerous cells. The tools used for that purpose include flow cytometric analysis and genetic expressions of pro-apoptotic (Bax) and the anti-apoptotic ( $\mathrm{Bcl}-2)$ gene markers.

Flow cytometric analysis is one of the most popular applications of studying apoptosis. It offers the ability to study large numbers of cells individually rather than a

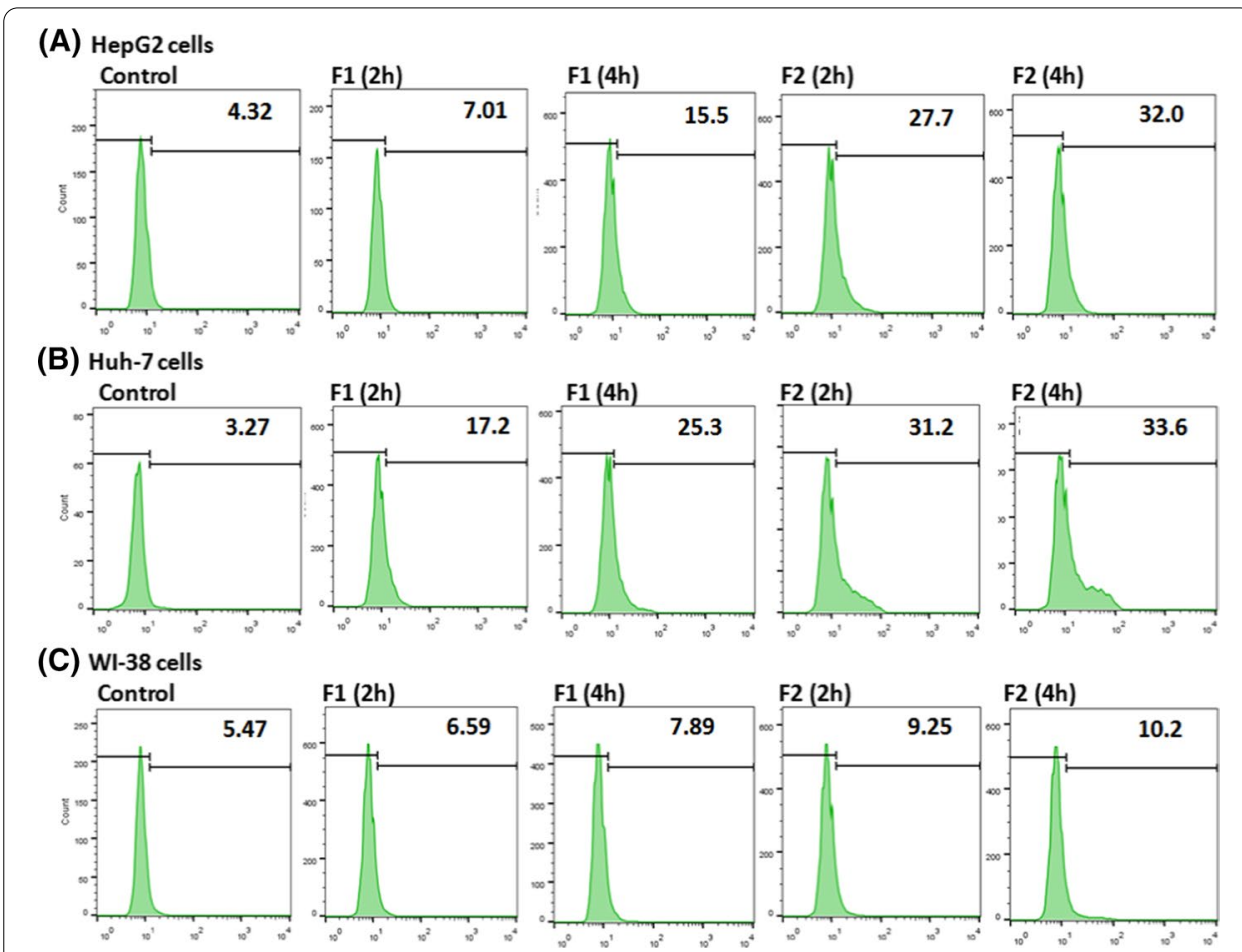

Fig. 5 Nanoparticles internalization (diffusion) in the HepG2 (a), Huh-7 (b), and WI-38 (c) cells, using labeled nanoemulsions (F1 and F2) with Alexa Flour 488. Cells were tracked for 2 and $4 \mathrm{~h}$ incubation 
mixed population. The technique can also be used to detect and quantify the level of apoptosis in a population of cells at static points or in a time course. Figure 6 shows the apoptotic diagram of the two HCC cells and normal WI-38 cells after treatment with the different formulations of $N$. sativa EO. From the figure it is evident that the count percent of HCC cells in the quadrant of negative annexin V/negative PI were decreased gradually in a significant manner after treatment with F0, F1, and F2, respectively. The same treatment shifted the cells into positive annexin V/positive PI quadrants leading to apoptotic cells. From Fig. 6 it is clear that nanoemulsion (F2) caused the highest significant induction rate of apoptosis compared to (F0) and (F1). In addition, Huh-7 cells showed less count percent than HepG2 cell line, indicating more sensitivity toward the treatment. These two conclusions came in accordance with our previous finding in the results concerning cytotoxicity evaluations. Figure 7 represents the graphs of the flow cytometric apoptotic screening diagram which was presented previously in (Fig. 7b). Un-apoptotic (Fig. 7a) and apoptotic cell percentages (Fig. 7b) elicit in detailed the same results that we previously discussed in Fig. 6.

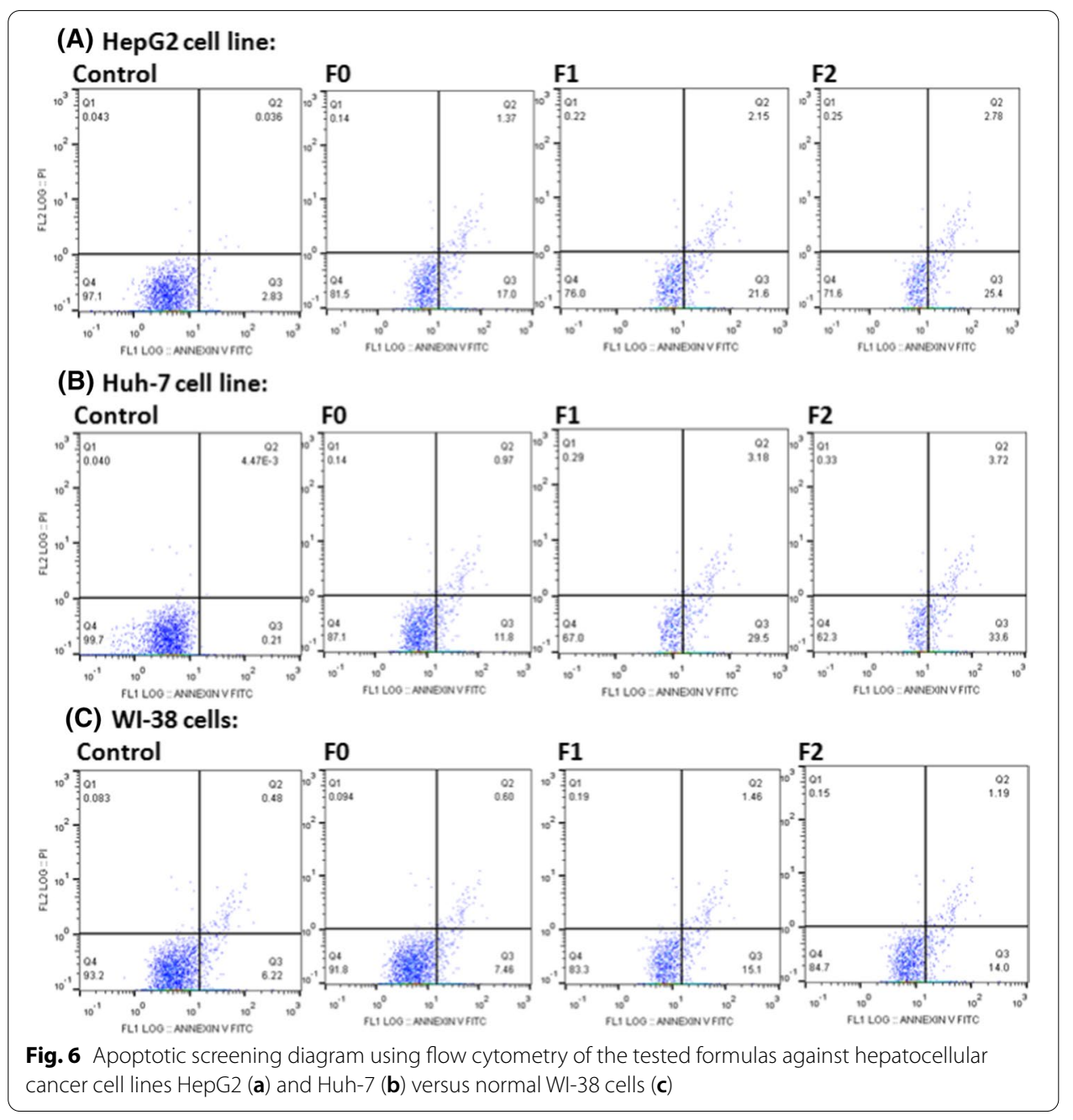



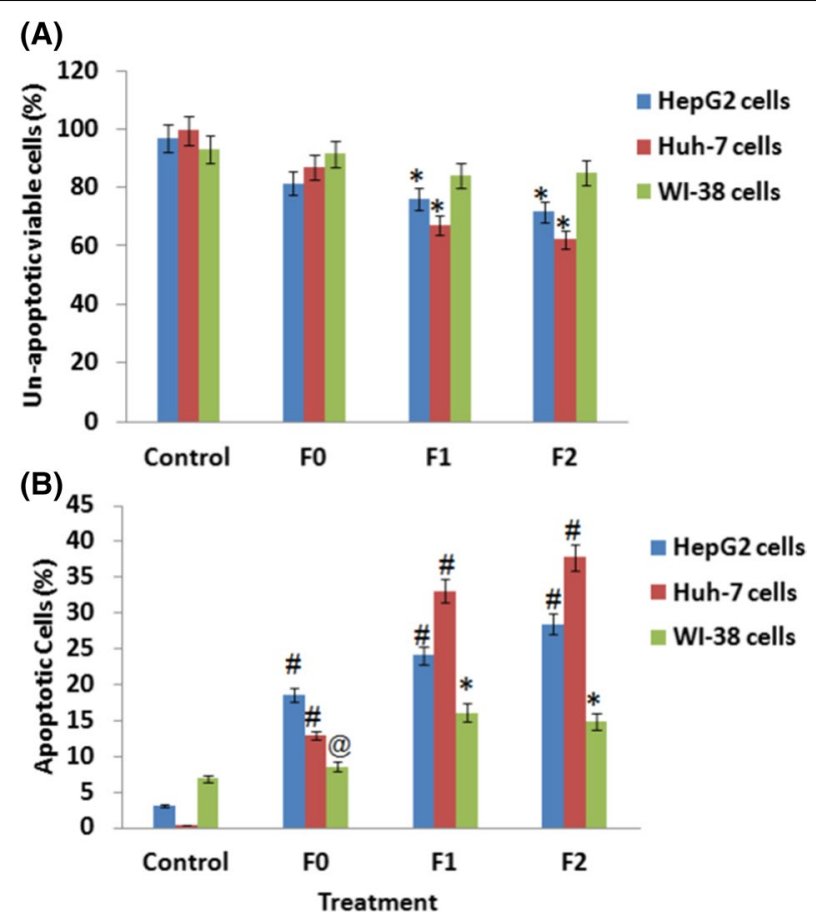

Fig. 7 Apoptotic graphs showing the un-apoptotic cells (a top) and apoptotic cells (b bottom) of $N$. sativa essential oil (F0) and its nanoemulsions (F1 and F2) against hepatocellular carcinoma cell lines HepG2 and Huh-7 in comparison to normal WI-38 cells. Control: untreated cells. Bars represent average of 3 replicates \pm SD. * Statistically significant decrease of treated cancer cells compared to control $(P<0.05)$. \#High statistically significant decrease of treated cancer cells compared to control $(P<0.01)$. ${ }^{\text {Non-significant }}$ change of treated WI-38 cells compared to control $(P>0.05)$.

\section{Gene expression of Bax and $\mathrm{BCl}-2$ genes}

Genetic expressions of pro-apoptotic (Bax) and the anti-apoptotic (Bcl-2) gene markers where evaluated in the current study (Fig. 8) to verify (support) the results obtained from the previously discussed apoptotic diagrams (Fig. 6). Data in Fig. 8a indicate that F0, F1 and F2 showed upregulation of Bax gene expression compared to the untreated normal cells (control). nanoemulsion (F2) showed the highest upregulating activity, and Huh-7 cells was the most responding to the treatment, as previously shown in the cytotoxic and apoptotic evaluations. In addition, nanoemulsion (F2) caused the highest significant downregulation of Bcl-2 genetic expression especially in Huh-7 compared to the normal cells (Fig. 8b).

The ratio of genetic expressions of pro-apoptotic (Bax) and anti-apoptotic (Bcl-2) is very important to confirm the apoptotic effect of any new treatment. Therefore, this ratio was calculated in the current study and shown in Table 5 . The data indicate that nanoemulsion (F2) has the highest Bax/Bcl-2 ratios especially for Huh-7 (69) followed by HepG2 (18) compared with normal cells (1.56). Nanoemulsion (F1) also showed high $\mathrm{Bax} / \mathrm{Bcl}-2$ ratio, but next to (F2) in activity, in which the ratio was 9.25 and 7.0 for HepG2 and Huh-7, respectively. On the other hand, the unformulated pure $N$. sativa EO (F0) recorded the least Bax/Bcl-2 ratios for HepG2 (2.25) and Huh-7 (2.71) compared with normal cells (1.09). This result indicates the significance of specially 

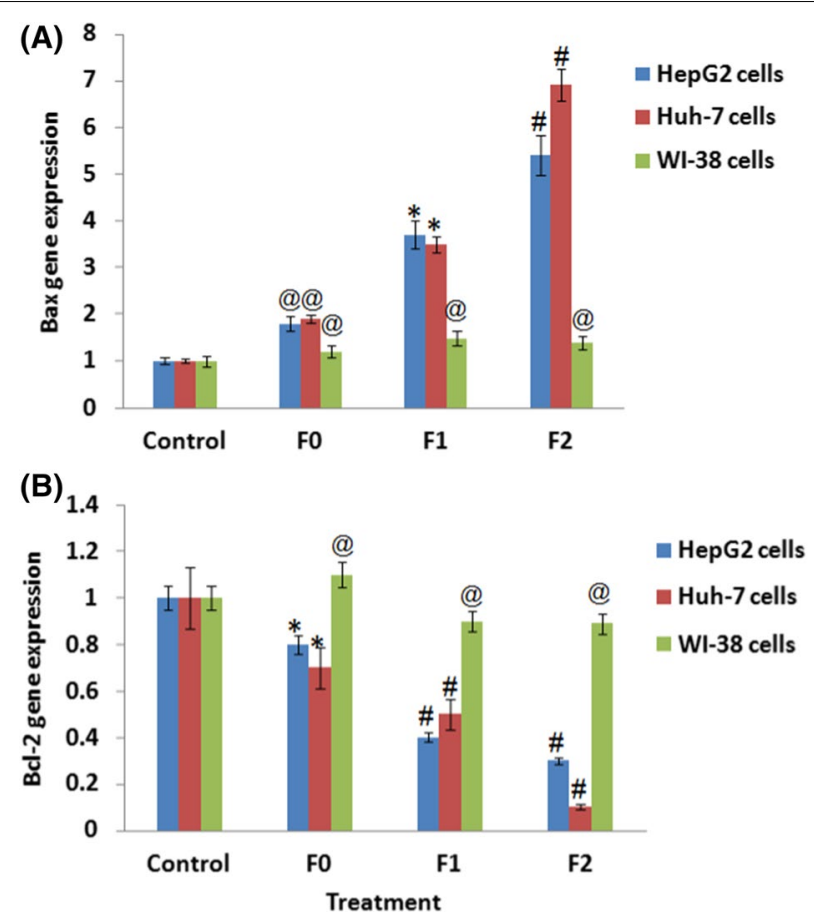

Fig. 8 Effect of N. sativa essential oil (F0) and its nanoemulsions (F1 and F2) against pro-apoptotic Bax gene and anti-apoptotic $\mathrm{BCl}-2$ gene. Control: untreated cells. Bars represent average of 3 replicates \pm SD. *Statistically significant decrease of treated cancer cells compared to control $(P<0.05)$. "High statistically significant decrease of treated cancer cells compared to control $(P<0.01)$. ${ }^{@}$ Non-significant change of treated WI-38 cells compared to control $(P>0.05)$

Table 5 The ratio of pro-apoptotic (Bax) to the anti-apoptotic ( $\mathrm{BCl}-2)$ gene markers (Bax/Bcl-2)

\begin{tabular}{llll}
\hline & F0 & F1 & F2 \\
\hline HepG2 cells & 2.25 & 9.25 & 18 \\
Huh-7 cells & 2.71 & 7 & 69 \\
Normal Wl-38 cells & 1.09 & 1.64 & 1.56 \\
\hline
\end{tabular}

tailored N. sativa EO nanoemulsion (F2) for modulating the pro-apoptotic and the anti-apoptotic genes for the favor of apoptosis.

\section{Measurements of ROS markers}

Measurements of ROS markers such as nitric oxide (NO) and malondialdehyde (MDA) were performed to confirm that EO nanoparticles in formula F1 and F2 induce ROSmediated apoptosis. Figure 9a, b shows, respectively, the levels of NO and MDA produced by HepG2 and Huh-7 cells upon treatments with F0, F1, F2 versus control. Both ROS markers (NO and MDA) were high significantly increased $(P<0.01)$ upon the treatment with F2 compared to the untreated control. On the other hand, F1 induced the significant elevation of NO levels, not MDA, specifically $(P<0.05)$. F0 slightly induced, but not in a significant manner $(P>0.05)$, the elevations of NO and MDA levels. We 

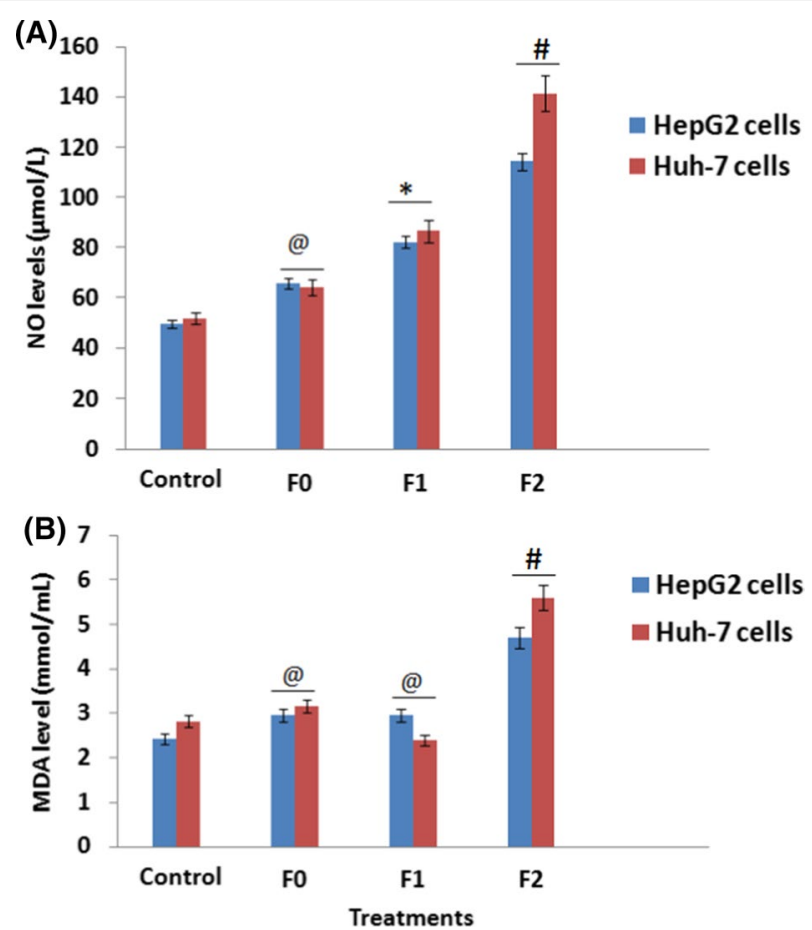

Fig. 9 ROS measurements, NO (a) and MDA (b), in liver cancer cell lines (HepG2 and Huh-7) upon treatment with N. sativa essential oil (F0) and its nanoemulsions (F1 and F2). *Statistically significant decrease of treated cancer cells compared to control $(P<0.05)$. \#High statistically significant decrease of treated cancer cells compared to control $(P<0.01)$. ${ }^{\circledR}$ Non-significant change of treated WI-38 cells compared to control $(P>0.05)$

concluded that F2 induced the elevations of both NO and MDA levels in cancerous cells, while F1 was specific for induction the elevation of only NO levels in cancerous cells.

\section{Safety of $N$. sativa and its nanoemulsions}

One of the common draw backs of anticancer chemotherapeutic drugs is its lack of selectivity (non-specificity), in their cytotoxic effect. This means that they could be cytotoxic to malignant as well as normal body cells resulting in little improvement on patient case. Therefore, the authors in the current study were keen to include a model of normal cells like WI-38 beside HCC cells in the evaluation of the cytotoxic and apoptotic activity of the different formulae of N. sativa EO. Data illustrated in Figs. 4, 5, 6 and 7 and Table 5 showed that the EO and its nanoemulsions have a minimal harmful effect on the normal WI-38 cells. These figures reflect the specificity of $N$. sativa EO formulae against HCC cells, while sparing normal WI-38 cells without harmful effects. That could be due to the reported selectivity of TQ, (31.2\% of EO composition) for induction of HCC to apoptosis (Jehan et al. 2020).

\section{Conclusions}

This in vitro study illustrates the cytotoxic and apoptotic potential of $N$. sativa essential oil against hepatocellular carcinoma cell lines. Formulation in nanoemulsion increased the cytotoxicity of the essential oil as revealed by inhibiting cell proliferation, decreasing $\mathrm{IC}_{50}$, enhancing apoptosis and upregulating the expression of apoptotic genes. The 
composition of the nanoemulsion especially the type of surfactant plays a significant role in enhancing the cytotoxicity of the essential oil. N. sativa EO and its nanoemulsions were found to be safe on normal cells, which indicate selective cytotoxicity. Overall, the results of this study provide additional insights on the application of $N$. sativa essential oil nanoemulsion as a potential adjuvant formula that selectively target $\mathrm{HCC}$ cells for treatment of liver cancer.

\section{Acknowledgements}

Not applicable.

\section{Authors' contributions}

AAA-R and AEE participated equally in the design, data curation, writing and revising of the manuscript. AEE was responsible for extraction, characterization of the plant extract and the formulation and characterization of nanoemulsions. AAA-R was responsible for the evaluation of cell culture, cancer cell propagation and subculturing, anticancer activity, flow cytometric experiments, and genetic expressions. Both authors read and approved the final manuscript.

\section{Funding}

Not applicable.

\section{Availability of data and materials}

The datasets used and/or analyzed during this study are available from the corresponding author on reasonable request.

\section{Declarations}

Ethics approval and consent to participate

An ethical approval for dealing with cell lines is granted to the author from the authority of Medical Research and Clinical Studies Institute.

\section{Consent for publication}

Not applicable.

\section{Competing interests}

No conflict of interest is associated with this work.

Received: 3 August 2021 Accepted: 22 October 2021

Published online: 04 November 2021

\section{References}

Abdel-Hamid N, Abass S, Mohamed A, Hamid D (2018) Herbal management of hepatocellular carcinoma through cutting the pathways of the common risk factors. Biomed Pharmacother 107:1246-1258

Abutaleb A, Almario J, Alghsoon S, Yoon J, Gheysens K, Kottilil S, Wilson E (2021) Higher levels of fibrosis in a cohort of veterans with chronic viral hepatitis are associated with extrahepatic cancers. J Clin Exp Hepatol 11:195-200

Afrose S, Junaid M, Akter Y, Tania M, Zheng M, Khan A (2020) Targeting kinases with thymoquinone: a molecular approach to cancer therapeutics. Drug Discov Today 25:2294-2306

Ahmad F, Ahmad F, Ashraf S, Saad H, Wahab S, Khan M, Ali M, Mohan S, Hakeem K, Athar T (2021) An updated knowledge of Black seed (Nigella sativa Linn.): review of phytochemical constituents and pharmacological properties. J Herb Med 25:100404

Anton A, Vandamme T (2009) The universality of low-energy nanoemulsification. Int J Pharm 377:142-147

Ashour A, Abd-Allah A, Korashy H, Attia S, Alzahrani A, Saquib Q, Bakheet S, Abdel-Hamied H, Jamal S, Rishi A (2014) Thymoquinone suppression of the human hepatocellular carcinoma cell growth involves inhibition of IL-8 expression, elevated levels of TRAIL receptors, oxidative stress and apoptosis. Mol Cell Biochem 389:85-98

Aslan M, Afşar E, Kırımlıoglu E, Çeker T, Yılmaz C (2021) Antiproliferative effects of thymoquinone in MCF-7 breast and HepG2 liver cancer cells: possible role of ceramide and ER stress. Nutr Cancer 73:460-472

Bashira A, El-Meserya M, Anwerb R, Eissa L (2020) Thymoquinone potentiates miR-16 and miR-375 expressions in hepatocellular carcinoma. Life Sci 254:117794

Beg S, Barkat A, Ahmad F (2020) Nanophytomedicine: concept to clinic. Springer, Singapore

Bhattacharjee M, Upadhyay P, Sarker S, Basu A, Das S, Ghosh A, Ghosh S, Adhikary A (2020) Combinatorial therapy of thymoquinone and Emodin synergistically enhances apoptosis, attenuates cell migration and reduces stemness efficiently in breast cancer. Biochim Biophys Acta (BBA) Gen Subj 1864:129695

Bimonte S, Albino V, Barbieri A, Tamma M, Nasto A, Palaia R, Molino C, Bianco P, Vitale A, Schiano R, Giudice A, Cascella M (2019) Dissecting the roles of thymoquinone on the prevention and the treatment of hepatocellular carcinoma: an overview on the current state of knowledge. Infect Agents Cancer 14:10-14

Claeys L, Romano C, De Ruyck K, Wilson H, Fervers B, Korenjak M, Zavadil J, Gunter M, De Saeger S, De Boevre M, Huybrechts I (2020) Mycotoxin exposure and human cancer risk: a systematic review of epidemiological studies. Compr Rev Food Sci Food Saf 19:1449-1464 
Dhamija E, Paul S, Kedia S (2019) Non-alcoholic fatty liver disease associated with hepatocellular carcinoma: an increasing concern. Indian J Med Res 149:9-17

Dubbelboer I, Pavlovic N, Heindryckx F, Sjögren E, Lennernäs H (2019) Liver cancer cell lines treated with doxorubicin under normoxia and hypoxia: cell viability and oncologic protein profile. Cancers 11:1024-1044

Edris A (2010) Evaluation of the volatile oils from different local cultivars of Nigella sativa L. grown in Egypt with emphasis on the effect of extraction method on thymoquinone. J Essent Oil-Bear Plants 3:154-164

Edris A, Wawrzyniak P, Kalemba D (2018) Subcritical $\mathrm{CO}_{2}$ extraction of a volatile oil-rich fraction from the seeds of Nigella sativa for potential pharmaceutical and nutraceutical applications. J Essent Oil Res 30:84-91

El-Najjar N, Chatila M, Mokaddam H, Vuorela H, Ocker M, Gandesiri M, Schneider-Stock R, Gali-Muhtasib H (2010) Reactive oxygen species mediate thymoquinone-induced apoptosis and activate ERK and JNK signalling. Apoptosis 15:183-195

El-Sayed H, Chizzola R, Ramadan A, Edris A (2017) Chemical composition and antimicrobial activity of garlic essential oils evaluated in organic solvent, emulsifying, and self-microemulsifying water-based delivery systems. Food Chem 221:196-204

Fan Y, Hou X, Guo P, Lv X, Zhao L, Wang H, Zhou L, Feng Y. Extraction of Amana edulis induces liver cancer apoptosis. EvidBased Complement Altern Med. 2018; Article ID: 3927075.

Fatfat M, Fakhoury I, Habli Z, Mismar R, Gali-Muhtasib H (2019) Thymoquinone enhances the anticancer activity of doxorubicin against adult T-cell leukemia in vitro and in vivo through ROS-dependent mechanisms. Life Sci 232:116628

Fröhlich T, Ndreshkjana B, Muenzner K, Reiter C, Hofmeister E, Mederer S, Fatfat M, El-Baba C, Gali-Muhtasib H, SchneiderStock R, Tsogoeva S (2017) Synthesis of novel hybrids of thymoquinone and artemisinin with high activity and selectivity against colon cancer. ChemMed Chem 12:226-234

Galindo-Alvarez J, Le K, Sadtler V, Marchal P, Perrin P, Tribet C, Marie E, Durand A (2011) Enhanced stability of nanoemulsions using mixtures of non-ionic surfactant and amphiphilic polyelectrolyte. Colloids Surf A Physicochem Eng Aspec 389:237-245

Groo A, Hedir S, Since M, Brotin E, Weiswald L, Paysant H, Nee G, Coolzaet M, Goux G, Delépée R, Freret T, Poulain L, VoisinChiret A, Malzert-Fréon A (2020) Pyridoclax-loaded nanoemulsion for enhanced anticancer effect on ovarian cancer. Int J Pharma 587:119655

Ha J, Jayaraman M, Radhakrishnan R, Gomathinayagam R, Yan M, Song Y, Isidoro C, Dhanasekaran D (2020) Differential effects of thymoquinone on lysophosphatidic acid induced oncogenic pathways in ovarian cancer cells. J Trad Complement Med 10:207-216

Hamed S, Shaaban H, Ramadan A, Edris A (2017) Potentials of enhancing the physicochemical and functional characteristics of Nigella sativa oil by using the screw pressing technique for extraction. Grasas Aceites 68:e188-e196

Jehan S, Zhong C, Li G, Bakhtiar S, Li D, Sui G (2020) Thymoquinone selectively induces hepatocellular carcinoma cell apoptosis in synergism with clinical therapeutics and dependence of p53 status. Front Pharmacol 11:555283

Kay R (1965) Effects of Tween 80 on the growth of the Ehrlich-Lettre ascites carcinoma. Experientia 21:644-645

Kokoska L, Urbanova K, Kloucek P, Nedorostova L, Polesna L, Malik J, Jiros P, Havlik J, Vadlejch J, Valterova I (2012) Essential oils in the Ranunculaceae family: chemical composition of hydrodistilled oils from Consolida regalis, Delphinium elatum, Nigella hispanica, and N. nigellastrum seeds. Chem Biodivers 9:151-161

Kubis A, Witek R, Olszewski Z et al (1979) The cytotoxic effect of Tween 80 on Ehrlich ascites cancer cells in mice. Pharmazie 34:745-746

Kumar S, Fayaz F, Pottoo F, Bajaj S, Manchanda S, Bansal H (2020) Nanophytomedicine based novel therapeutic strategies in liver cancer. Curr Top Med Chem 20:1-26

Li Y, Martin R (2011) Herbal medicine and hepatocellular carcinoma: applications and challenges. Evid Based Complement Altern Med 2011:541209

Li Y, Shi X, Zhang J, Zhang X, Martin C (2014) Hepatic protection and anticancer activity of curcuma: a potential chemopreventive strategy against hepatocellular carcinoma. Int J Oncol 44:505-513

Majdalawieh A, Fayyad M (2016) Recent advances on the anti-cancer properties of Nigella sativa, a widely used food additive. J Ayurveda Integr Med 7:173-180

Manivannan S, Nagaraj S, Narayan S (2021) A reflection on the mechanism of the role of nanoparticles in increasing the efficacy of anti-tumour properties of docetaxel. Curr Pathobiol Rep. https://doi.org/10.1007/s40139-021-00223-3

Miranda S, Lemos J, Fernandes R, Silva J, Ottoni F, Townsend D, Rubello D, Alves R, Cassali G, Ferreira L, de Barros A (2021) Enhanced antitumor efficacy of lapachol-loaded nanoemulsion in breast cancer tumor model. Biomed Pharmacother 133:110936

Periasamy V, Athinarayanan J, Alshatwi A (2016) Anticancer activity of an ultrasonic nanoemulsion formulation of Nigella sativa L. essential oil on human breast cancer cells. Ultrason Sonochem 31:449-455

Ruman U, Fakurazi S, Masarudin M, Hussein Z (2020) Nanocarrier-based therapeutics and theranostics drug delivery systems for next generation of liver cancer nanodrug modalities. Int J Nanomed 15:1437-1456

Sajid M, Cameotra S, Khan M, Ahmad I (2018) Chapter 23, Nanoparticle-based delivery of phytomedicines: challenges and opportunities. In: Khan M, Ahmad I, Chattopadhyay D (eds) New look to phytomedicine advancements in herbal products as novel drug leads, 1st edn. Academic Press, London, pp 597-623

Salehi F, Jamali T, Kavoosi G, Ardestani S, Vahdati S (2021) Stabilization of Zataria essential oil with pectin-based nanoemulsion for enhanced cytotoxicity in monolayer and spheroid drug-resistant breast cancer cell cultures and deciphering its binding mode with gDNA. Int J Biol Macromol 164:3645-3655

Schneider-Stock R, Fakhoury I, Zaki A, El-Baba C, Gali-uhtasib H (2014) Thymoquinone: fifty years of success in the battle against cancer models. Drug Discov Today 19:18-30

Shaaban S, Negm A, Ibrahim E, Elrazak A (2014) Chemotherapeutic agents for the treatment of hepatocellular carcinoma: efficacy and mode of action. Oncol Rev 8:246-256

Shaaban H, Sadek Z, Edris A, Hussain A (2015) Analysis and antibacterial activity of Nigella sativa essential oil formulated in microemulsion system. J Oleo Sci 64:223-232

Silva A, Haris P, Serralheiro M, Pacheco R (2020) Mechanism of action and the biological activities of Nigella sativa oil components. Food Biosci 38:100783 
Thomsen K, Christensen A, Meyer M (2020) Awareness of alcohol as a risk factor for cancer: a population-based crosssectional study among 3000 Danish men and women. Prev Med Rep 19:101156

Tije A, Verweij J, Loos W, Sparreboom A (2003) Pharmacological effects of formulation vehicles: implications for cancer chemotherapy. Clin Pharmacokin 42:665-685

Tubtimsri S, Limmatvapirat C, Limsirichaikul S, Akkaramongkolporn P, Piriyaprasarth S, Patomchaiviwat V, Limmatvapirat S (2021) Incorporation of fixed oils into spearmint oil-loaded nanoemulsions and their influence on characteristic and cytotoxic properties against human oral cancer cells. J Drug Deliv Sci Technol 63:102443

Upadhyay T, Ansari V, Ahmad U, Sultana N, Akhtar J (2020) Exploring nanoemulsion for liver cancer therapy. Curr Cancer Ther Rev 16:1-9

Vo T, Ta Q, Chu Q, Nguyen T, Vo V (2020) Anti-hepatocellular cancer activity exerted by $\beta$-sitosterol and $\beta$-sitosterolglucoside from Indigofera zollingeriana Miq. Molecules 25:3021-3034

Zhang M, Du H, Wang L, Yue Y, Zhang P, Huang Z, Lv W, Ma J, Shao Q, Ma M, Liang X, Yang T, Wang W, Zeng J, Chen G, Wang X, An J (2020) Thymoquinone suppresses invasion and metastasis in bladder cancer cells by reversing EMT through the Wnt/ $\beta$-catenin signaling pathway. Chemo-Biol Interact 320:109022

Zhang R, Wu T, Zheng P, Liu M, Xu G, Xi M, Yu J (2021) Thymoquinone sensitizes human hepatocarcinoma cells to TRAILinduced apoptosis via oxidative DNA damage. DNA Repair 103:103117

\section{Publisher's Note}

Springer Nature remains neutral with regard to jurisdictional claims in published maps and institutional affiliations.

- fast, convenient online submission

- thorough peer review by experienced researchers in your field

- rapid publication on acceptance

- support for research data, including large and complex data types

- gold Open Access which fosters wider collaboration and increased citations

- maximum visibility for your research: over 100M website views per year

At BMC, research is always in progress.

Learn more biomedcentral.com/submissions 